\title{
METABOLIC DISEASE
}

\section{G206 BIOCHEMICAL CONTROL OF PHENYLKETONURIA IN} CHILDREN IN WALES

$\underline{\text { Schmidt M }}$, Bradley D, Shortland G University of Wales, Heath Park,Cardiff CF4 4XW

In 1993 the MRC Working Party on Phenylketonuria (PKU) published recommendations on the management of PKU in children. We have analyzed the levels available in the newborn screening laboratory in Cardiff and at the Royal Gwent Hospital from 1995 to 1999 to assess to which degree children in Wales with classical PKU achieve the recommended control. 23 children are managed by one consultant and dietician with a special interest in metabolic disease, general Paediatricians manage 23 children.

Children managed at specialist clinic $(n=23)$

\begin{tabular}{lllll}
\hline $\begin{array}{l}\text { Age } \\
\text { years }\end{array}$ & $\begin{array}{l}\text { No of Tests } \\
\% \text { of expected }\end{array}$ & \multicolumn{3}{l}{ Phenylalanine Concentration(\%) } \\
Within Target & $>50 \%$ above Target & $>100 \%$ above Target \\
\hline $0-4$ & 81.8 & 64.4 & 7.2 & 2.0 \\
$4-10$ & 70.2 & 67.5 & 6.4 & 1.5 \\
$10-15$ & 83.1 & 77.8 & 2.3 & 0.8 \\
\hline
\end{tabular}

Children managed at their local hospital $(n=23)$

\begin{tabular}{|c|c|c|c|c|}
\hline \multirow{2}{*}{$\begin{array}{l}\text { Age } \\
\text { years }\end{array}$} & \multirow{2}{*}{$\begin{array}{l}\text { No of Tests } \\
\% \text { of expected }\end{array}$} & \multicolumn{3}{|c|}{ Phenylalanine Concentration(\%) } \\
\hline & & Within Target & $>50 \%$ above Target & $>100 \%$ above Target \\
\hline $0-4$ & 53.6 & 52.4 & 9.3 & 11.6 \\
\hline $4-10$ & 45.2 & 41.7 & 10.7 & 3.9 \\
\hline $10-15$ & 68.2 & 60 & 0 & 20 \\
\hline
\end{tabular}

How achievable the recommended target ranges are is yet unclear and depends among other factors on the severity of the enzyme deficiency. The difference in control between children managed in a specialist clinic as opposed to small numbers managed in general paediatric clinics may have implications for the long-term provision of care.

\section{G207 OBESITY, INSULIN RESISTANCE AND DIABETES-A DEMOGRAPHIC TIME-BOMB}

Ehtisham $\mathrm{S}^{1}$, Agwu $\mathrm{JC}^{2}$, Barrett $\mathrm{TG}^{3}$, Kirk $\mathrm{JMW}^{3}$, Frost $\mathrm{G}^{4}$, Swift $\mathrm{P}^{5}$, Shaw $\mathrm{NJ}^{3}$ City Hospital ${ }^{1}$ and The Children's Hospital ${ }^{3}$, Birmingham, Sandwell ${ }^{2}$ and Kidderminster ${ }^{4}$ District General Hospitals, Leicester Royal Infirmary ${ }^{5}$

Introduction: The prevalence of obesity in childhood is increasing and is a recognised risk factor for the development of diabetes. Children from ethnic minorities are now presenting with obesity and type II diabetes.

Aims: The aim of this study was to identify and characterise children with Type II diabetes in the Midlands.

Methods: Cases were identified by contacting paediatricians responsible for children with diabetes in five hospitals. Details were collected on demographics, mode of presentation, investigations and treatment on a standard proforma.

Results: We identified eight girls age 9-16 years who were of Pakistani, Indian or Arab origin. They were all overweight (percentage weight for height $140-206 \%$ ) and had a family history of diabetes in at least two generations. They presented insidiously with hyperglycaemia and glycosuria without ketosis and five were asymptomatic. Five had systolic blood pressures above the $95^{\text {th }}$ centile at presentation. Islet cell antibodies were measured in six and were negative. Four had acanthosis nigricans which is a cutaneous marker of insulin resistance and the other four had high plasma levels of insulin and/or c-peptide. These patients are distinct from those with maturity-onset diabetes of youth (MODY) who do not show insulin resistance.

Conclusions: We present the first UK case reports of Type II diabetes in children. Paediatricians need to be aware of the risk of Type II diabetes developing in childhood in high risk ethnic groups, particularly in association with obesity and a positive family history.

\section{G208 WILSON'S DISEASE IN CHILDREN: PREDICTORS OF OUTCOME THIRTY YEARS EXPERIENCE AT KING'S COLLEGE HOSPITAL}

A Dhawan, P D'Silva, RM Taylor, P Cheeseman, E Katsiyiannakis, AJ Baker, N Hadzic, G Mieli-Vergani Department of Child Health, King's College Hospital, London

The case notes of 52 children (28 male) with Wilson's Disease (WD) diagnosed between 1968-1998 were reviewed. The patients were divided in two groups; Group $1(n=9)$ required liver transplant or died, and Group $2(n=43)$ alive and well on chelation therapy. The presenting features included jaundice in 39 (Gr1/Gr2; 9/30: $p<0.001$ ), ascites in 11 (6/5: $p<0.01$ ). The following features were not statistically different in Gr1 and Gr2: mean age 12 and 10 years, oesophageal varices in 1 and 1 , abdominal pain in 4 and 6 , Kayser Fleisher rings in 6 and 21, anorexia and lethargy in 6 and 9. Gp1/Gp2 mean INR (international normalised ratio) was 2.9/1.3, $\mathrm{p}<0.0001$; total bilirubin 409/20 $\mu \mathrm{Mol} / \mathrm{L}, \mathrm{p}<0001$; AST 239/108 U/L, $\mathrm{p}<0.001$; alkaline phosphatase 148/324
$\mathrm{U} / \mathrm{L}, \quad \mathrm{p}=\mathrm{ns}$; albumin $27 / 37 \mathrm{~g} / \mathrm{L}, \quad \mathrm{p}<0.01$; serum copper $17.5 / 5.5 \mu \mathrm{Mol} / \mathrm{L}$ $\mathrm{p}<0.0001$; haemoglobin $9.8 / 12.1 \mathrm{~g} / \mathrm{dL}, \mathrm{p}<0.02$. A receiver operative curve was plotted to achieve the highest area under the curve to predict the prognostic value of the laboratory parameters. A combination of INR $>1.5$, total bilirubin $>100 \mu \mathrm{Mol} / \mathrm{L}$ and serum copper $>12 \mu \mathrm{Mol} / \mathrm{L}$ had $100 \%$ sensitivity, $97 \%$ specificity and $89 \%$ positive predictive value, in predicting the outcome of WD at presentation. The triad of INR $>1.5$, total serum bilirubin of $>100 \mu \mathrm{Mol} /$ $L$ and serum copper of $>12 \mu \mathrm{Mol} / \mathrm{L}$ at diagnosis appears to be a good prognostic marker as to the outcome of WD in children and may help in identifying the patients where liver transplantation should be considered.

\section{G209 THE SIGNIFICANCE OF REDUCED RESPIRATORY CHAIN ENZYME ACTIVITY IN MUSCLE BIOPSY SAMPLES} OBTAINED FROM CHILDREN

Mordekar $\mathrm{S}^{1}$, Bonham $\mathrm{JR}^{2}$, Guthrie $\mathrm{P}^{3}$, Baxter $\mathrm{P}^{1}$, and Heales $\mathrm{SJ}^{4}$ Departments of ${ }^{1}$ Paediatric Neurology, ${ }^{2}$ Chemical Pathology, ${ }^{3}$ Molecular Genetics, Sheffield Children's Hospital, Sheffield, S10 2TH, UK and ${ }^{4}$ Department of Neurochemistry, Institute of Neurology, London, WC1N 3BG, UK

Respiratory chain enzyme activity determined in muscle biopsy tissue can be reduced in individuals with mitochondrial disease but may also be downregulated in other muscle disorders such as those of neurogenic origin. In an attempt to assess the significance of such changes, the results obtained from 73 children ( 40 male, 33 female; mean age $4 \mathrm{y} 3 \mathrm{mo}$, range $1 \mathrm{mo}-15 \mathrm{y}$ $2 \mathrm{mo}$ ) suspected of having a mitochondrial disorder were reviewed. The patients were allocated into one of three groups on a weighted point scoring system using independent criteria believed to be associated with mitochondrial disease. These included: the presence of a known mtDNA mutation -6 points; elevated CSF lactate $(>4.0 \mathrm{mmol} / \mathrm{L})$, ragged red fibres, patchy/reduced COX/ SDH staining - 4 points; unexplained multisystem disease affecting two or more organ systems, MRI changes suggestive of mitochondrial disease -2 points; a suggestive family history, other suggestive clinical features, other suggestive laboratory findings -1 point. Those patients scoring 4 or more were placed in group 1 - "likely", those scoring 2 or 3 were placed in group 2 - "possible" and those scoring only one point were placed in group 3 "unlikely". The frequency of reduced respiratory chain enzyme activity was assessed in each group: group I - 9/22 (41\%), group $2-7 / 34(21 \%)$, group $3-1 / 17(6 \%)$. The severity of the reduction in activity, expressed as, mean residual activity compared with the lower limit of normal, was also compared by group : Group 1, mean residual activity = 63\%; group 2 , mean residual activity $=83 \%$.

The results suggest that, in these patients, respiratory chain enzyme activity measured in muscle biopsy tissue is pathologically related to mitochondrial disease. However, they also suggest that an isolated and modest reduction in activity without other supportive features should not be taken to indicate mitochondrial disease Grouping in this way can also help identify patients in whom respiratory chain enzyme measurement may not be justified.

\section{G210 NEONATAL HAEMOCHROMATOSIS IN SIXTEEN CHILDREN FROM TWELVE FAMILIES: PATTERN OF PRESENTATION AND OUTCOME}

F Rodrigues ${ }^{1}$, M Kallas ${ }^{1}$, R Nash ${ }^{2}$, J Sandell ${ }^{1}$, L D'Antiga ${ }^{1}$, G Mieli-Vergani ${ }^{1}$ Departments of Child Health ${ }^{1}$ and Histopathology ${ }^{2}$ - King's College Hospital, London, UK

Neonatal haemochromatosis $(\mathrm{NH})$ is an uncommon disease in which liver injury is associated with massive iron deposition sparing the reticular-endotheial system. The role of antioxidant and iron chelation therapy is controversial. To review clinical and laboratorial features, treatment and outcome of patients with $\mathrm{NH}$, we analysed the medical records of 16 children (7 males) from 12 families referred to us between 1990-98. In 8/12 families the proband followed an unaffected first child. Nine families had further children and in 7 the disease recurred. In one family 2 children from different fathers were affected. One child with a positive family history had a pre-natal diagnosis of $\mathrm{NH}$ suggested by cordocentesis showing abnormal liver function tests and clothing at 30 weeks of gestation. 11/16 presented on day 1 with hypoglycaemia and 4 in the first week ( 3 with jaundice and 1 with lethargy). Ferritin level was elevated in all patients (median: $2403 \mathrm{ng} / \mathrm{ml}$ ) and was significantly higher than in controls. Median AST was $122 \mathrm{iU} / \mathrm{L}$ and bilirubin 221 ?mol/l. Hypoalbuminemia and coagulopathy were present in all. Liver histology, available in 15, showed parenchymal collapse, diffuse fibrosis, proliferation of "neocholangioles" and moderate to severe haemosiderin deposition. Extra-hepatic siderosis was demonstrated by $\mathrm{MRI}$ in 2 (pancreas) and by post-mortem examination in 10 (pancreas $=8$, myocardium $=6$, thyroid gland $=5$, kidney $=3$, adrenal glands $=2$ and salivary glands=1). Measured iron concentration was elevated in all cases of $\mathrm{NH}$ and higher than in controls. 7/9 patients received a chelation-antioxidant cocktail (1), 3 in the first day of life and 4 between week 1 and 3 . Three died and the other 4 required liver transplantation (LT) of whom 2 died. One of 9 infants who did not receive the cocktail survived, 3 died and 5 required LT of whom 3 died. 
Overall 11 died and 5 ( 4 transplanted) are alive after a median follow up of 2 yrs (range: 1-5), with no recurrence of the disease. In conclusion $\mathrm{NH}$ is a disease starting prenatally and presenting at birth with severe liver disease and diffuse iron overload. A first unaffected sibling is frequent but the risk of recurrence in following pregnancies is high. The prognosis is poor. Chelation/antioxidant treatment is not effective in severe cases and LT is the only curative option.

(1) Pediat Res 1993;33:109A 